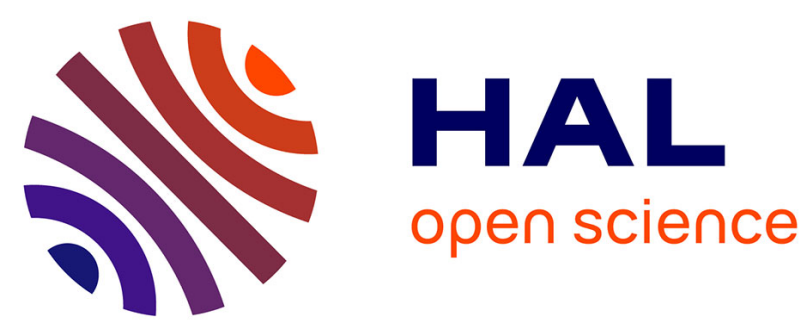

\title{
Measuring market power for food retail activities: French evidence
}

\author{
Alexandre Gohin, Herve Guyomard, . Esr. Département d'Economie Et \\ Sociologie Ruralesdijon
}

\section{To cite this version:}

Alexandre Gohin, Herve Guyomard, . Esr. Département d'Economie Et Sociologie Ruralesdijon. Measuring market power for food retail activities: French evidence. 1. Séminaire "Jeunes chercheurs", Dec 1997, Dourdan, France. 13 p. hal-02839368

\section{HAL Id: hal-02839368 https://hal.inrae.fr/hal-02839368}

Submitted on 7 Jun 2020

HAL is a multi-disciplinary open access archive for the deposit and dissemination of scientific research documents, whether they are published or not. The documents may come from teaching and research institutions in France or abroad, or from public or private research centers.
L'archive ouverte pluridisciplinaire HAL, est destinée au dépôt et à la diffusion de documents scientifiques de niveau recherche, publiés ou non, émanant des établissements d'enseignement et de recherche français ou étrangers, des laboratoires publics ou privés.

\section{(ㅇ)(1) $\$$}

Distributed under a Creative Commons Attribution - NonCommercial - NoDerivatives| 4.0 


\section{Premier séminaire "Jeunes Chercheurs "}

Gohin Alexandre (INRA-Rennes)

DOCUMENTATION ÉCONOMIE RURALE RENNES

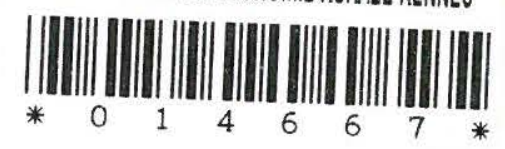

17-18 décembre 1997. Dourdan 



\title{
Measuring market power for food retail activities: French evidence
}

\author{
Alexandre Gohin et Hervé Guyomard ${ }^{1}$ \\ INRA-ESR, 65 rue de Saint-Brieuc, 35042 Rennes cedex, France
}

December 1997

\section{Introduction}

The estimation of market power has been a prominent component of empirical industrial organisation over the past fifteen years. There are now many papers in which the methods of New Empirical Industrial Organisation (NEIO) have been applied to evaluate the degree of market power of a specific industry on the output market on the basis of demand and cost functions and hypotheses concerning the strategic interactions among firms. Following the pioneering work of Gollop and Roberts (1979), and Appelbaum (1979, 1982), many studies consider the case of a single output industry characterised by an oligopolistic structure in the output market and use the "conjectural-variation" or "conjectural-elasticity" modelling approach where firms choose their output levels given their beliefs, i.e., their conjectural variations, about rivals' reactions to their output choice. This basic modelling framework has been extended to include the multioutput structure of the considered industry (Gelfand and Spiller, 1987 ; Schroeter and Azzam, 1990 ; Wann and Sexton, 1992), the possibility that the considered firms exert market power simultaneously on both the output and input markets (Schroeter, 1988 ; Azzam and Pagoulatos, 1990 ; Wann and Sexton ; Murray, 1995), or the existence of policy regulations (Rude, 1992 ; Oxley, 1994).

While there are numerous applications of this approach to various manufacturing industries (in particular, food industries), and more recently to export markets (see, e.g., Karp and Perloff, 1989, 1993 ; Deodhar and Sheldon, 1995, 1997), the retail industry has received only very limited attention in this context. This is hardly justifiable since the retail industry is particularly important for studies of welfare. The objective of this paper is then to estimate the degree of imperfect competition in the French food retail industry using a structural econometric model based on the formulation and estimation of a multioutput cost function for this industry, a set of supply functions for the "oligopsoned" inputs, i.e., the wholesale goods, and a set of demand functions for the "oligopoled" outputs, i.e., the final goods.

The theoretical framework adopted in this paper draws heavily on Schroeter and Azzam (1990) who developed and estimated an economic model for measuring market power in a quantity-setting oligopoly engaged in the joint production of demanded-related goods. The French food retail industry technology is restricted to be of fixed proportions between each

\footnotetext{
${ }^{1}$ The authors would like to thank C. Le Mouel and Y. Surry for many helpful suggestions and comments on an earlier draft of this paper while absolving them of all blame for any errors or shortcomings that remain.
} 
final good and the corresponding wholesale good, but additional factors of production are employed in variable proportions. The assumption of fixed proportions implies that the conjectural elasticities are identical in the input and output markets (Schroeter). This theoretical framework is applied to a time series of aggregate data for the French food retail industry. As it is often the case in empirical industrial organisation work, firm-level data are not available. The model is thus estimated at the industry level and we briefly discuss the conditions to be maintained in order to ensure a consistent aggregation of firm-specific functions and equilibrium conditions to industry-wide counterparts. Applying the "conjectural-elasticity" approach to the French food retail industry is also compounded with data problems, in particular the lack of available data for prices and quantities of additional factors of production. We also discuss this issue. We finally present and interpret the results, especially the conduct parameters, i.e., the conjectural elasticities, and the degree of oligopsony-oligopoly power for the three goods we consider, i.e., fresh milk and dairy products, meat products and other food products. The final section concludes.

\section{Theoretical framework}

Consider a non-competitive retail industry in which $N$ firms produce, i.e., distribute, $M$ homogeneous final goods. At least some of the $N$ firms offer the $M$ goods while the others may specialise in the distribution of some of them. To put these final goods at consumers' disposal, a retail firm $j$ buys the corresponding wholesale goods and employs a set of additional factors of production to produce the bundle of services which is incorporated into the wholesale goods. Each firm $j$ exercises some market power in purchasing wholesale goods and in selling final goods, but is a price taker in the market for additional factors of production.

The relationship between the wholesale good input and the final good output is assumed to be one of fixed proportions. Without loss of generality, units of measurement are defined so that input and output quantities can be represented by the same variable, i.e., $Q_{i}^{j}$ for the quantity of the "input-output" $i$ which is used and produced by the $j t h$ firm. Accordingly, $Q^{j}$ is the vector of "input-output" quantities which are used and produced by the jth firm. Additional factors of production, $X_{k}^{j}, k=1, \ldots, K$, are employed in variable proportions. It follows that the total cost of distribution for the $j t h$ firm, $C T^{j}\left(Q^{j}, w, \eta, C F^{j}\right)$, may be defined as:

(1) $C T^{j}\left(Q^{j}, w, \eta, C F^{j}\right) \equiv \sum_{i=1}^{M} w_{i} \cdot Q_{i}^{j}+C^{j}\left(Q^{j}, \eta\right)+C F^{j}$

where $\eta$ is the price vector of additional factors of production, $w$ is the purchasing price vector of wholesale goods, $C^{j}\left(Q^{j}, \eta\right)$ are variable costs of additional factors of production, and $C F^{j}$ are fixed costs.

Let the wholesale market supply curve facing the retail industry for the $i t h$ wholesale good be given by:

(2) $Q_{i}=S_{i}\left(w_{i}, Y\right)$ 
where $Y$ is a vector of exogenous variables, and $\partial S_{i}(.) / \partial w_{i}>0$.

Let the final market demand curve facing the retail industry for the ith final good be given by:

(3) $Q_{i}=D_{i}(p, Z)$

where $p$ is the price vector of final goods, $Z$ are exogenous factors, and $\partial D_{i}(.) / \partial p_{i}<0$. Profits for the $j t h$ retail firm are given by:

(4) $\pi^{j}=\sum_{i=1}^{M} p_{i} \cdot Q_{i}^{j}-\sum_{i=1}^{M} w_{i} \cdot Q_{i}^{j}-C^{j}\left(Q^{j}, \eta\right)-C F^{j}$

The problem for the $j t h$ firm is then to choose the optimal quantities $Q_{i}^{j^{*}}, i=1, \ldots, M$, which maximise its profit (4) given the nature of its environment defined by equations (2) and (3). From (3), one notes that the $M$ final goods are assumed to be demand related which implies that all final good quantities defined at the industry level enter each of the $M$ inverse final demand functions. But, from (2), one notes that the $M$ wholesale goods are assumed to be supply independent which implies that the inverse wholesale supply function for good $i$ does not depend on aggregate quantities of other wholesale goods. Assuming an interior solution for all quantities, profit maximisation under oligopoly-oligopsony yields the following firstorder conditions: ${ }^{1}$

(5a) $p_{i}-w_{i}-\partial C^{j}(.) / \partial Q_{i}^{j}+\sum_{m=1}^{M} \sum_{l=1}^{M}\left(\frac{\partial p_{m}}{\partial Q_{l}}\right) \cdot\left(\frac{\partial Q_{l}}{\partial Q_{i}^{j}}\right) \cdot Q_{m}^{j^{*}}-\sum_{m=1}^{M}\left(\frac{\partial w_{m}}{\partial Q_{m}}\right) \cdot\left(\frac{\partial Q_{m}}{\partial Q_{i}^{j}}\right) \cdot Q_{m}^{j^{*}}=0$

or, equivalently,

$$
p_{i}-w_{i}-\partial C^{j}(.) / \partial Q_{i}^{j}=-\left(\frac{1}{Q_{i}^{j *}}\right) \cdot \sum_{m=1}^{M} \sum_{l=1}^{M} \varepsilon_{m l} \cdot \theta_{l i}^{j} \cdot p_{m} \cdot Q_{m}^{j^{*}}+\left(\frac{1}{Q_{i}^{j^{*}}}\right) \cdot \sum_{m=1}^{M} \gamma_{m m} \cdot \theta_{m i}^{j} \cdot w_{m} \cdot Q_{m}^{j^{*}}
$$

where

$\varepsilon_{m l}=\left(\partial p_{m} / \partial Q_{l}\right) \cdot\left(Q_{l} / p_{m}\right)$ is the industry elasticity of the inverse final demand for the $m t h$ final good with respect to the quantity of the $l$ th final good,

$\theta_{l i}^{j}=\left(\partial Q_{l} / \partial Q_{i}^{j}\right) \cdot\left(Q_{i}^{j} / Q_{l}\right)$ is the $j t h$ retail firm's conjectural elasticity of market quantity for the $l$ th good with respect to the quantity of the ith good used and produced by this firm, and $\gamma_{m m}=\left(\partial w_{m} / \partial Q_{m}\right) \cdot\left(Q_{m} / w_{m}\right)$ is the industry elasticity of the inverse wholesale supply for the $m$ th wholesale good with respect to the quantity of this wholesale good.

At this stage, the two following remarks are in order. First, industry elasticities of the inverse wholesale supply for the $m t h$ wholesale good with respect to the quantity of the lth wholesale good, $l \neq m$, are by assumption equal to zero. In other words, we have $\gamma_{m l}=0$ for $l \neq m$. Second, since the relationship between the wholesale good input $i$ and the final good output $i$ is assumed to be one of fixed proportions, the output or final good market conjectural elasticity of firm $j$ for the $l$ th good with respect to the quantity of the ith good and the input or wholesale good market conjectural elasticity of firm $j$ for the lth good with respect to the quantity of the $i t h$ good coincide. If, in addition, we assume that market crossconjectural elasticities equal zero, i.e., $\theta_{l i}^{j}=0, i \neq l$, equation $(5 \mathrm{~b})$ reduces to: 
(6) $p_{i}-w_{i}-\partial C^{j}(.) / \partial Q_{i}^{j}=-\left(\frac{\theta_{i i}^{j}}{Q_{i}^{j^{*}}}\right) \cdot\left[\sum_{m=1}^{M} \varepsilon_{m i} \cdot p_{m} \cdot Q_{m}^{j^{*}}-\gamma_{i i} \cdot w_{i} \cdot Q_{i}^{j^{*}}\right]$

From (6), it appears that the conjectural elasticity $\theta_{i i}^{j}$ is the crucial conduct parameter. It lies between zero when the behaviour of the considered firm is competitive and one for a monopoly-monopsony behaviour. In the first case, the right-hand side term of (6) is null and this equation reduces to the usual condition that final good output price equals total marginal cost. At the other extreme, if this parameter equals one, equation (6) defines the optimality conditions for a final good monopoly - wholesale good monopsony. In that second case, total marginal cost equals perceived net marginal revenue where the latter includes cross-output market effects via cross-quantity elasticities of inverse final demand functions.

To summarise, we assume a homogeneous product, quantity-setting game in which retail firms have conjectural variations which allows us to distinguish between collusion, CournotNash competition and price taking. The proposed analytical framework cannot thus be used to capture the possibility of oligopolistic-oligopsonistic price-setting behaviour since with homogeneous goods, the latter collapses into the competitive equilibrium. Gasmi et al. (1992) extend the traditional conjectural variation model to the case of differentiated products with two control variables, price and advertising. Carter and MacLaren (1997) follow the approach of Gasmi et al. to test the competing hypotheses of price versus quantity setting in the case of the Japanese market for imported beef. More generally, Corts (1996) argues that the traditional conjectural variation model fails to measure market power accurately since "without stipulating the true nature of the behaviour underlying the observed equilibrium, no inference about the extent of market power can be made from analysis of the observed variables". One must therefore bear in mind that any conclusions that can be drawn from our analysis rests on the assumption of a homogeneous product, quantity-setting game and the premise that the conjectural variation model allows us to identify and measure market power.

\section{Empirical implementation}

\section{Aggregation issues}

Because our application uses aggregate data, it is useful to consider the problems raised by aggregation in the multiinput-multioutput case. These issues have been largely discussed in the literature (see, e.g., Appelbaum; Schroeter and Azzam ; Wann and Sexton ; Murray) and they are consequently only briefly presented in this paper.

For cost functions to be well defined at the industry level, the retail firm total cost function (1) must be of the Gorman polar form with nonjointness in production, i.e.,

$$
C T^{j}\left(Q^{j}, w, \eta, C F^{j}\right) \equiv \sum_{i=1}^{M} w_{i} \cdot Q_{i}^{j}+G^{j}(\eta)+\sum_{i=1}^{M} H_{i}(\eta) \cdot Q_{i}^{j}+C F^{j}
$$

From (7), it follows that the total marginal cost of a final good $i$ is constant across retail firms $j, j=1, \ldots, N$. For a given firm $j$, it does not depend on output $i$ level neither on quantities of other final goods produced by this firm, i.e., 
(8) $\partial C T^{j}(.) / \partial Q_{i}^{j}=w_{i}+H_{i}(\eta)$

The second aggregation issue concerns interpretation of the conjectural elasticities. Following Appelbaum, and Wann and Sexton, we assume that at equilibrium conjectural elasticities are the same for all retail firms, i.e., $\theta_{l i}^{j}=\theta_{l i} \quad \forall j=1, \ldots, N$. As noted by Wann and Sexton, this second assumption can be achieved without loss of generality since the assumption of constant total marginal costs of distribution has been maintained in order to ensure consistent aggregation of costs to the industry level.

Multiply equation (6) by $Q_{i}^{i^{*}}$, sum over all retail firms $j$ and divide by industry quantity $Q_{i}^{*}$, one yields:

(9a) $p_{i}-w_{i}-H_{i}(\eta)=-\left(\frac{\theta_{i i}}{Q_{i}^{*}}\right) \cdot\left[\sum_{m=1}^{M} \varepsilon_{m i} \cdot p_{m} \cdot Q_{m}^{*}-\gamma_{i i} \cdot w_{i} \cdot Q_{i}^{*}\right]$

or, equivalently,

(9b) $p_{i}=w_{i}+H_{i}(\eta)-\theta_{i i} \cdot \sum_{m=1}^{M}\left(\frac{Q_{m}^{*}}{Q_{i}^{*}}\right) \cdot \varepsilon_{m i} \cdot p_{m}+\theta_{i i} \cdot \gamma_{i i} \cdot w_{i}$

\section{Empirical model specification}

Equation ( $9 b$ ) is used as a basis for testing the significance of market power of retail firms in both the wholesale good and final good markets. To identify the various parameters entering this equation, i.e., $\theta_{i i}, \varepsilon_{m i}$ and $\gamma_{i i}, i=1, \ldots, M, m=1, \ldots, M$, the estimation procedure must combine the information contained in equation (9b) with that of supply functions for wholesale goods and demand functions for final goods. In other words, the complete aggregate model is made of equations (2), (3) and (9b).

For each wholesale good, we specify the input supply function (2) faced by the retail industry as a simple linear form, i.e.,

(10) $Q_{i}=a_{i}+b_{i} \cdot w_{i}+c_{i} \cdot t$

where $t$ is a time trend, and $a_{i}, b_{i}$ and $c_{i}$ are parameters to be estimated.

From (10), own price elasticities of supply may easily be computed as:

(11) $\mu_{i}=\left(1 / \gamma_{i i}\right)=b_{i} \cdot\left(w_{i} / Q_{i}\right)$

As empirical specification for the final demand set, i.e., for equations (3), we use a Linear Expenditure System (LES). The system of expenditure equations for the $M$ final goods is thus defined as (see, e.g., Johnston et al., 1984):

$$
p_{m} \cdot Q_{m}=p_{m} \cdot d_{m}+e_{m} \cdot\left(R-\sum_{m=1}^{M} p_{m} \cdot d_{m}\right) \quad m=1, \ldots, M
$$

where $R=\sum_{m=1}^{M} p_{m} \cdot Q_{m}$, and $d_{m}$ and $e_{m}$ are parameters to be estimated. 
For the system of equations represented by (12), uncompensated own and cross price elasticities are, respectively:

(13a) $\delta_{m m}=\left(1 / \varepsilon_{m m}\right)=-1+\left(1-e_{m}\right) \cdot\left(d_{m} / Q_{m}\right)$

(13b) $\delta_{m i}=\left(1 / \varepsilon_{m i}\right)=-e_{m} \cdot\left[\left(p_{i} \cdot d_{i}\right) /\left(p_{m} \cdot Q_{m}\right)\right]$

The final empirical issue concerns specification of functions $H_{i}(\eta)$. Since the prices $\eta$ of additional factors of production are not available in the database, we heroically assume that the total marginal cost of distribution for each final good $i$ may simply be defined as the sum of the purchasing price of the corresponding wholesale good, $w_{i}$, and a linear function of a time trend, $t$. In other words, we assume that $H_{i}(\eta)=f_{i}+g_{i} . t, \forall i=1, \ldots, M$, where $f_{i}$ and $g_{i}$ are parameters to be estimated. It is clear that this specification is one of the main weak points of our analysis. Nevertheless using some possible alternatives, like an index of wages defined at the national level instead of a time trend, leads to the same conclusions concerning market power estimates of the French food retail industry.

\section{Data}

For purposes of empirical analysis, the French food retail industry is assumed to produce three final goods, i.e., dairy products $(i=1)$, meat products $(i=2)$ and an aggregate of other food products $(i=3)$. The latter includes non processed agricultural products. Data for estimation are supplied by the Institut National de la Statistique et des Etudes Economiques (INSEE). They are annual and cover the 1977-1993 period. Final good implicit price series $(1980=1)$ are derived by dividing expenditures in current French francs by expenditures in constant Francs. Marketing margins are directly available from input-output tables. Unit marketing margins for the three considered goods can be calculated by dividing marketing margins by corresponding quantities. Using final good implicit price series, one can then define wholesale good implicit price series.

\section{Econometric model specification}

Input supply equations (10) may be used to yield an estimate of the industry elasticity of the inverse supply for each wholesale good, i.e., $\gamma_{i i}$. Similarly, the system of expenditure equations (12) may be used to obtain an estimate of own and cross industry elasticities of inverse demands for each final good, i.e., $\varepsilon_{m m}$ and $\varepsilon_{m i}$. A two-step procedure estimation may then be used by directly incorporating these parameters into equations (9b) which are simultaneously estimated to obtain an estimate of the three industry conjectural elasticities, i.e., $\theta_{i i}, i=1, \ldots, M=3$. Given the potential problems associated with this two-step estimation procedure (see, e.g., Love, 1992), we prefer to jointly estimate supply equations (10), final demand equations (12) and optimality conditions (9b) as a system of simultaneous equations. The errors are assumed to be additive and jointly normally distributed with zero mean and constant variance-covariance matrix. To avoid singularity of the latter, one of the expenditure equations in the sub-system of final demand is deleted from the estimated model. In practice, the third expenditure equation corresponding to other food products is omitted. The empirical model consisting of three supply equations, two expenditure equations and three first-order conditions is estimated using the iterative Three-Stage Least Squares (3iSLS) procedure, which Hausman (1985), e.g., showed to be asymptotically equivalent to Full Information 
Maximum Likelihood (FIML) and which provides consistent and asymptotically efficient estimates. We treat all explaining variables (except the time trend) as endogenous variables and we use one-year lagged variables as instruments. As noted by, e.g., Appelbaum, the problem with the instrument variables method is that it may be sensitive to the choice of instruments. Nevertheless it is reassuring to note that 3iSLS and FIML estimates do not differ substantially and lead to the same conclusions concerning market power estimates of the French food retail industry.

\section{Empirical results and discussion}

The parameter estimates and t-ratios, as well as the conventional $R^{2}$ (calculated as one minus the residual sum of squares to the total sum of squares in each equation) and the Durbin-Watson statistics are given in Table 1. The estimated equations fit the data quite well, as indicating by the $R^{2}$ coefficients all in excess of 0.96 except for the supply function of other food products $\left(R^{2}=0.86\right)$. The t-ratios indicate that all but three parameters are statistically significant at least at the five per cent level. Furthermore the three insignificant parameters are constant estimates in marginal cost functions. Parameter estimates for the linear expenditure sub-system show that the marginal budget shares are positive and that the minimum consumption levels for the three commodities are positive, ranging from 37215 for dairy products to 156201 for other food products. The three income elasticities are positive. Dairy products and other food products have estimated income elasticities that are greater than one (1.15 and 1.16, respectively, in average over the estimation period), suggesting that some commodities within these groups are luxuries. On the contrary, meat products have estimated income elasticities that are less than one, 0.56 in average over the estimation period. The three income elasticities have remained fairly stable over the whole period. Compensated and uncompensated own price elasticities of final demand are negative. In average over the period, uncompensated own price elasticities are -0.42 for dairy products, -0.28 for meat products and -0.79 for other food products. The uncompensated own price elasticities for dairy products and meat products have experienced an increase (in absolute value) over the estimation period, from -0.30 in 1978 to -0.49 in 1993 for dairy products, and from -0.21 in 1978 to -0.32 in 1993 for meat products. The uncompensated own price elasticity for other products has remained stable. As expected, all compensated cross price elasticities of final demand are positive. Uncompensated cross price elasticities of final demand are all negative indicating that the three goods are gross complements. The three estimated supply functions are increasing in prices and very inelastic as would be expected, i.e., 0.171 for dairy products, 0.075 for meat products and 0.292 for other food products, in average over the estimation period.

\section{(insert Table 1)}

The discussion now focuses on conjectural elasticity parameters which measure the degree of market imperfection for the three considered commodities. For each good, computing tstatistics provide a simple test of the price-taking assumption by suggesting acceptance or rejection of price-taking $\left(\theta_{i i}=0\right)$ at a specified level of significance. One easily verifies that each conjectural elasticity estimate is significantly different from zero at the five per cent level of significance. The hypothesis that these distortion parameters are all identically zero 
$\left(\theta_{11}=\theta_{22}=\theta_{33}=0\right)$ is also rejected at the five per cent level of significance. Correspondingly the hypothesis that a product has been characterised by monopsony-monopoly behaviour $\left(\theta_{i i}=1\right)$ is rejected at the same level of significance.

For each commodity, the degree of oligopsony-oligopoly power may be measured by the Lerner-analog index which is defined as:

$$
L_{i}=\frac{p_{i}-w_{i}-H_{i}(\eta)}{p_{i}-w_{i}}=\frac{-\theta_{i i} \cdot\left[\sum_{m=1}^{M}\left(\frac{Q_{m}^{*}}{Q_{i}^{*}}\right) \cdot \varepsilon_{m i} \cdot p_{m}-\gamma_{i i} \cdot w_{i}\right]}{p_{i}-w_{i}}
$$

The Lerner indexes are presented in Table 2. The sample mean values of these indexes are 0.68 for dairy products, 0.56 for meat products and 0.63 for other food products. Accordingly, for dairy products and in average over the study period, $68 \%$ of the unit margin of food retail firms is explained by the oligopsony-oligopoly power of these firms. The corresponding percentages are $56 \%$ for meat products and $63 \%$ for other food products. These estimates suggest that on the average of the study period, the unit margin for dairy products is $212 \%$ higher than in the competitive case. The corresponding percentages are $127 \%$ for meat products and $170 \%$ for other food products.

The values of Lerner indexes are continuously and regularly declining over time for the three commodities, suggesting that market power decreases over time. The declining trend in market power of French food retail firms is a priori counter-intuitive since the increase in mergers and acquisitions, as well as the accelerated closing of small, family-operated and specialised food retailers should lead, on contrary, to an augmented market power on the belief that increased concentration implies augmented anticompetitive bchaviour. ${ }^{2}$

At this stage, it is first interesting to note that most studies which measure market power in oligopolies and/or oligopsonies for different food industries also find a declining trend in market power while market concentration increases. As an example, Schroeter and Azzam (1991) identify a decreasing trend in market power for the US beef packing industry over the 1976-88 period of increasing market concentration. Hamilton and Sunding (1997) develop a theoretical framework to explain such a result. They allow for cost differences among food processors and endogenize entry and exit. Under these conditions, they show that increasing concentration (measured by the Lerner index) and decreasing market power are likely to occur simultaneously in response to a shift in farm supply. Let us consider, e.g., the case where the farm supply curve is inelastic which implies that market power in the processing industry is high, farm prices are low and numerous inefficient high-cost firms are able to produce (relative to the case of elastic supply). "When technical change causes the supply of raw products to become more elastic, the farm supply curve is able to more readily absorb increases in production without creating large, commensurate increases in the price of raw products. Incumbent firms consequently expand their use of raw products, increasing farm prices and precipitating the exist of high-cost firms in the industry." In other words, a clockwise rotation of the farm supply curve leads to a decrease in market power while market concentration increases due to the exit of inefficient high-cost processors.

From a more empirical point of view, one plausible explanation of the declining trend in market power in the French food retail industry may be the following. One can reasonably expect that variable distribution costs of food retail firms increase over the study period. ${ }^{3}$ Incentives to increase capacity utilisation levels in order to achieve significant cost economies 
(by spreading costs over a larger volume of sales) may then offset incentives to exert market power by restricting input use and output sale. In other words, retail firms may seek maximal growth of sales by assuring the necessary flow of inputs to operate near maximal capacity rather than maximal profits. Complementary and/or alternative explanations which merit further investigation may also be proposed. For example, one may reasonably expect that in a contracting market price competition is more intense in order to sustain volume of sales. One can also reasonably suppose that fixed costs are relatively more important for small and specialised food retailers than they are for supermarkets. Accordingly small and specialised firms may behave so as to equate price and average cost. Our measure of market power is then upward biased, particularly for the first years of our sample where the number of these small and specialised firms was larger.

Finally, it is important to underline that our empirical model constrains the conjectural elasticity parameters to be constant. This is clearly a weak point of our analysis which may have an impact on our empirical results and may also explain, at least partially, the estimated declining trend in market power. From (14), one verifies that high (in absolute value) demand and supply price elasticities tend to yield low Lerner-analog indexes, other things equal and in particular for constant conjectural elasticity estimates. The degree of market imperfection and market power is negatively associated with factors that intensify price competition in input and output markets. As an example, Schroeter and Azzam (1990) assume that the conjectural elasticity parameter is a negative function of capacity utilisation level where the latter is used as an indicator for firms to intensify competition. Using a similar argument, Murray assumes that the conjectural elasticity parameter is a positive function of transport costs per unit distance. Because of the lack of statistical information, it was not possible in our case to estimate a model where the three conjectural elasticity parameters were specified as a function of proxies which reflect an intensified or conversely a decreased competition. Furthermore it is important to note that it is very difficult to give a sound economic content to such functions which remain very ad-hoc.

(insert Table 2)

\section{Concluding remarks}

This paper develops and estimates an empirical model of pricing behaviour for retail firms in both a quantity-setting oligopoly engaged in the joint production of demand-related final goods and a quantity-setting oligopsony for supply-unrelated wholesale goods. The procedure consists of simultaneously estimating a system of demand functions for final goods, supply functions for wholesale goods and the retail industry first-order profit-maximisation conditions, from which an estimate of the degree of imperfect competition and of oligopolyoligopsony power for the different commodities can be retrieved. The procedure adopted draws thus on a method of identifying and measuring market power that has been developed by Gollop and Roberts, and Appelbaum, and that has extensively been applied to various industries in the manufacturing sector, as well as to export markets. To our knowledge, it is the first time that the methods of NEIO are applied to the retail industry.

The model is applied to the French food retail industry. Three commodities are distinguished, i.e., dairy products, meat products and other food products. Since a summary and a discussion of empirical results has already been provided in the previous section, here we simply note 
that i) we strongly reject the hypothesis that French food retail firms behave competitively and ii) more than 50 per cent of the wholesale-to-retail price margins for the three goods are attributable to oligopoly-oligopsony distortions.

The empirical model incorporates certain simplifying assumptions, such as the specification of supply functions for wholesale goods and marginal cost functions for retail firms, that limits its practical relevance. Market conduct parameter estimates are subject to important caveats stemming mainly from the imposition of these strong assumptions. Further research is clearly necessary using more refined and more detailed data sets to verify the robustness of our empirical results.

\section{References}

Appelbaum, E. (1979). Testing price taking behavior. Journal of Econometrics. 9, 283-294. Appelbaum, E. (1982). The estimation of the degree of oligopoly power. Journal of Econometrics. 19, 287-299.

Azzam, A.M., and E. Pagoulatos (1990). Testing oligopolistic and oligopsonistic behaviour: An application to the US meat-packing industry. Journal of Agricultural Economics. 41, 362-370.

Barla, P. (1997). Firm Size Inequality and Market Power. Working paper, Université Laval, Québec, Canada.

Betancourt, R., and D.A. Gautschi (1992). The outputs of retail activities: French evidence. Applied Economics. 24, 1043-1052.

Carter, C.A., and D. MacLaren (1997). Price or quantity competition? Oligopolistic structures in international commodity markets. Review of International Economics. 5, 373-385.

Corts, K.S. (1996). Conduct parameters and the measurement of market power: the impossibility of astructural inference. Working paper, Harvard Business School, Boston.

Deodhar, S.Y., and I.M. Sheldon (1995). Is foreign trade (im)perfectly competitive? An analysis of the German market for banana imports. Journal of Agricultural Economics. 46, 336-348.

Deodhar, S.Y., and I.M. Sheldon (1997). Market power in the world market for soymeal exports. Journal of Agricultural and Resource Economics. 22, 78-86.

Gasmi, F., Laffont J.J., and Q. Vuong (1992). Econometric analysis of collusive behavior in a soft-drink market. Journal of Economics and Management Strategy. 1(2), 277-311.

Gelfand, M.D., and P.T. Spiller (1987). Entry barriers and multiproduct oligopolies: Do they forbear or spoil? International Journal of Industrial Organization. 5, 101-113.

Gollop, F.M., and M.J. Roberts (1979). Firm interdependencies in oligopolistic markets. Journal of Econometrics. 10, 313-331.

Hamilton, S.F., and D.L. Sunding (1997). The Effect of Farm Supply Shifts on Concentration and Market Power in the Food Processing Sector. American Journal of Agricultural Economics. 79, 524-531.

Hausman, J.A. (1985). An instrumental variable approach to full information estimators for linear and certain nonlinear econometric models. Econometrica. 43, 727.738.

Johnson, S.R., Hassan, Z.A., and R.D. Green (1984). Demand Systems Estimation: Methods and Applications. The Iowa State University Press, Ames.

Karp, L., and J.M. Perloff (1989). Oligopoly in the rice export market. Review of Economics and Statistics. 71, 462-470. 
Karp, L., and J.M. Perloff (1993). A dynamic model of oligopoly in the coffee export market. American Journal of Agricultural Economics. 75, 448-457.

Love, H.A. (1992). Econometric analysis of imperfect competition and implications for trade research. In Sheldon, I.M. and Henderson, D.R., eds., Industrial Organization and International Trade: Methodological Foundations for International Food and Agricultural Market Research, Columbus, OH: The Ohio State University.

Murray, B.C. (1995). Measuring oligopsony power with shadow prices: U.S. markets for pulpwood and sawlogs. The Review of Economics and Statistics. 77, 486-498

Oxley, J.C. (1994). Public research effects on the Canadian food processing industry: a dynamic optimisation approach. Unpublished Ph.D. Thesis. University of Guelph, Guelph, Ontario.

Rude, J. (1992). The impact of trade liberalisation on the Canadian dairy processing sector. Unpublished Ph.D. Thesis. University of Guelph, Guelph, Ontario.

Schroeter, J.R. (1988). Estimating the degree of market power in the beef packing industry. Review of Economics and Statistics. 70, 158-162.

Schroeter, J.R., and A.M. Azzam (1990). Measuring market power in multi-product oligopolies: The US meat industry. Applied Economics. 22, 1365-1376.

Schroeter, J.R., and A.M. Azzam (1991). Marketing margins, market power, and price uncertainty. American Journal of Agricultural Economists. 73, 990-991.

Wann, J.J., and R.J. Sexton (1992). Imperfect competition in multiproduct food industries with applications to pear processing. American Journal of Agricultural Economics. 72, 980990. 
Table 1. Parameter estimates (t-ratios in parentheses), $R^{2}$ and Durbin-Watson statistics (2)

\begin{tabular}{|c|c|c|c|}
\hline \multirow[b]{2}{*}{ Parameter } & \multicolumn{3}{|c|}{ Commodity group } \\
\hline & Dairy products & Meat products & Other food products \\
\hline$a_{i}$ & $37999.7 \quad(28.25)$ & $91288.6(47.71)$ & $163213.0 \quad(26.09)$ \\
\hline$b_{i}$ & 8108.3 (4.68) & 7696.23 (2.93) & $70895.5 \quad(11.26)$ \\
\hline$c_{i}$ & $730.3 \quad(8.60)$ & 801.6 (7.77) & $-(2)$ \\
\hline$d_{i}$ & $37214.9(8.70)$ & $90362.4 \quad(20.77)$ & $156201.0 \quad(7.67)$ \\
\hline$e_{i}$ & 0.1547 (11.69) & $0.1499 \quad(10.05)$ & $0.6954 \quad(35.26)$ \\
\hline$f_{i}$ & $-0.01705 \quad(-0.46)$ & $-0.03877 \quad(-0.72)$ & $-0.01631 \quad(-0.42)$ \\
\hline$g_{i}$ & $0.01409 \quad(2.77)$ & $0.02580 \quad(7.44)$ & $0.02373 \quad(8.31)$ \\
\hline$f_{i} . D 84$ (1) & $0.0676 \quad(2.75)$ & - & - \\
\hline$g_{i} . D 84(1)$ & $-0.7028 \mathrm{E}-02 \quad(-2.47)$ & - & - \\
\hline$\theta_{i i}$ & $0.54778 \mathrm{E}-02 \quad(2.41)$ & $0.44350 \mathrm{E}-02 \quad(2.62)$ & $0.02732 \quad(4.87)$ \\
\hline
\end{tabular}

\begin{tabular}{llc}
\hline & \multicolumn{2}{c}{ Statistics } \\
\cline { 2 - 3 } Equation & $R^{2}$ & $D W$ \\
\hline $\begin{array}{l}\text { Supply } \\
\text { dairy products }\end{array}$ & 0.9945 & 1.52 \\
meat products & 0.9670 & 1.30 \\
ot. food products & 0.8596 & 0.29 \\
LES & & \\
dairy products & 0.9993 & 1.49 \\
meat products & 0.9996 & 2.19 \\
Optimality cond. & & \\
Dairy products & 0.9997 & 1.60 \\
meat products & 0.9981 & 1.88 \\
ot. food products & 0.9992 & 1.33 \\
\hline
\end{tabular}

(1) $D 84$ is a dummy variable that takes into account the milk quota regime introduced in 1984. It takes a value of zero over the 1977-1983 period and one over the 1984-1993 period.

(2) The hypothesis of no serial correlation was tested against the alternative of first-order serial correlation. It was rejected in two supply functions (i.e., for dairy products and other food products) and in the final demand sub-system. When the supply function for other food products was corrected for serial correlation, we were not able to obtain convergence. In the same way, when the dependant variable was specified as a linear function of time in this equation, the estimate of $b_{i}$ was negative. Accordingly only the supply function for dairy products and the final demand sub-system were corrected for first-order serial correlation in Table 1, and the estimated supply function for other food products does not depend on time. 
Table 2. Estimated degrees of market power (Lerner-analog indexes)

\begin{tabular}{llll}
\hline Year & Dairy products & Meat products & Other food products \\
\hline 1978 & 0.9123 & 0.9148 & 0.8584 \\
1979 & 0.8326 & 0.7905 & 0.7893 \\
1980 & 0.7769 & 0.7068 & 0.7360 \\
1981 & 0.7395 & 0.6527 & 0.7038 \\
1982 & 0.7136 & 0.6188 & 0.6778 \\
1983 & 0.6885 & 0.5834 & 0.6535 \\
1984 & 0.6423 & 0.5560 & 0.6369 \\
1985 & 0.6383 & 0.5283 & 0.6143 \\
1986 & 0.6342 & 0.5037 & 0.5947 \\
1987 & 0.6268 & 0.4832 & 0.5776 \\
1988 & 0.6210 & 0.4662 & 0.5626 \\
1989 & 0.6196 & 0.4580 & 0.5502 \\
1990 & 0.6152 & 0.4464 & 0.5394 \\
1991 & 0.6073 & 0.4318 & 0.5320 \\
1992 & 0.5988 & 0.4188 & 0.5134 \\
1993 & 0.5914 & 0.4030 & 0.5034 \\
Mean & & & 0.6277 \\
\hline
\end{tabular}

End notes

${ }^{1}$ If the $j t h$ firm does not produce the $k$ th good, $Q_{k}^{j^{*}}=0$ and $\partial \pi^{j}\left(Q^{j^{*}}\right) / \partial Q_{k}^{j} \leq 0$. In order to encompass both the interior solution and the corner regimes where the considered retail firm specialises in the distribution of some goods only, equation ( $5 \mathrm{~b}$ ) may be written as:

$$
\left(p_{i}-w_{i}-\partial C^{j}(.) / \partial Q_{i}^{j}\right) \cdot Q_{i}^{j^{*}}=-\sum_{m=1}^{M} \sum_{l=1}^{M} \varepsilon_{m l} \cdot \theta_{l i}^{j} \cdot p_{m} \cdot Q_{m}^{j^{*}}+\sum_{m=1}^{M} \gamma_{m m} \cdot \theta_{m i}^{j} \cdot w_{m} \cdot Q_{m}^{j^{*}} \quad i=1, \ldots, M
$$

We allow for some quantities to be equal zero at the firm level, but the equilibrium industry quantity of each good is strictly positive.

${ }^{2}$ A concentration index encompasses two aspects, i.e., the number of firms and the size distribution of competitors. It must decline with the number of firms and it must increase with the level of inequality among firms. It is now well recognised that market power increases when the number of firms declines, but the assumed positive link between market power and firm size inequality for a given number of firms is less obvious. On this point, see Barla (1997) who finds that there exits a non-linear U-shaped relationship between market power and firm size inequality in the case of the US airline industry.

${ }^{3}$ Retail firms provide consumers with a large variety of distribution services: accessibility of location, assortment, assurance of product delivery in the desired form and at the desired time, information and ambience. Higher levels of these services cost the firms more and reduce the costs for consumers (Betancourt and Gautschi, 1992). 
